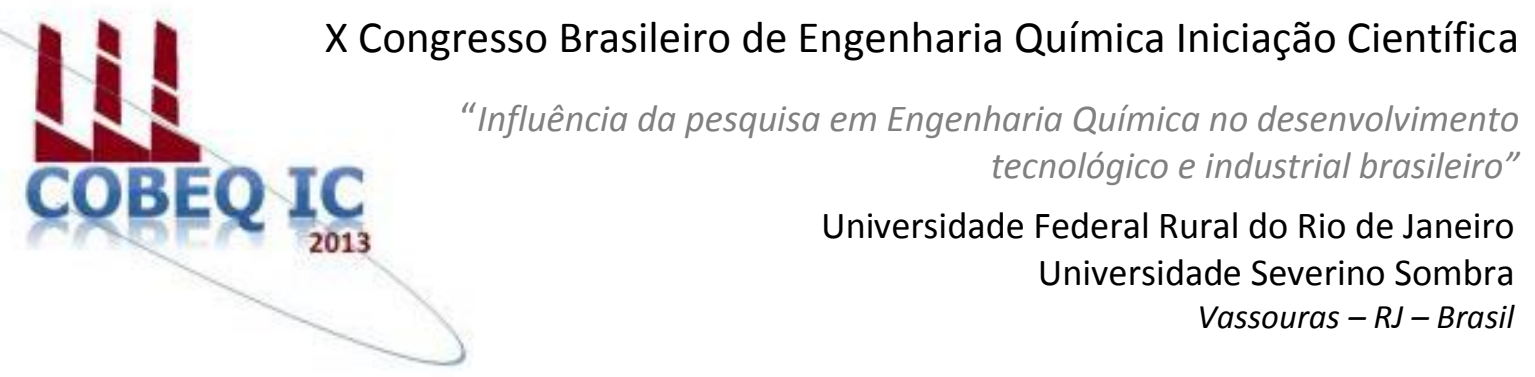

\title{
COMPARAÇÃO ENTRE AQUECEDORES SOLARES COM LIGAÇÕES EM SERPENTINA E PARALELA $(* *)$
}

\author{
SIQUEIRA*1, L. B.; TEIXEIRA*1, L. T., RAMOS*1, S. S. e S.M.S. ROCHA ${ }^{2}$ \\ ${ }^{1}$ Alunos do DETEC/UFES ${ }^{2}$ Professor do DETEC/UFES \\ Departamento de Engenharia e Tecnologia - Centro Universitário Norte do Espírito \\ Santo - Universidade Federal do Espírito Santo, \\ CEUNES, BR101, Km 60, São Mateus, CEP 29932-540, ES, e-mail: \\ sandra.m.rocha@ufes.br
}

\begin{abstract}
RESUMO - O aquecimento de água para banho humano utilizando energia solar é uma tecnologia conceituada no Brasil, porém o alto custo dos sistemas convencionais impossibilita a utilização deste método para a grande maioria da população. Na tentativa de difundi-la entre as populações de baixa renda, este trabalho investigou e comparou à eficiência energética de dois sistemas de aquecimento de água com placas planas construídas de garrafas de Polietileno (PET) e embalagens cartonadas. Um teve a conexão em serpentina e o outro em paralelo, conectados a um reservatório sem boiler. Os dois protótipos foram testados no mesmo horário em dias com alta incidência solar. $\mathrm{O}$ aquecedor com conexão tipo serpentina atingiu a temperatura máxima de $62{ }^{\circ} \mathrm{C}$, causando degradação dos canos PVC e interrupção do fluxo de água. As placas com conexão paralela tiveram a temperatura máxima de $51,5{ }^{\circ} \mathrm{C}$. Este trabalho permitiu concluir que os dois arranjos podem ser utilizados para o aquecimento de água para banho humano, porém o arranjo com ligação tipo paralela apresenta maior vantagem para a instalação nas residências, visto que apresenta uma temperatura média próxima da ideal para o banho humano $\left(40^{\circ} \mathrm{C}\right)$, bem como maior facilidade de construção e operação.
\end{abstract}

Palavras chave: Aquecimento de Água, Aquecedores solar de Baixo custo; Material reciclável.

\section{INTRODUÇÃO}

O novo padrão de consumo da população nas últimas décadas, além do desenvolvimento econômico intrínseco ao novo padrão também culminou em preocupações com o uso de matérias primas e insumos. Dentre estes, a matriz energética mundial merece destaque, visto que o petróleo apesar de seu grande potencial poluidor e decrescimento na produção atual ainda é a principal fonte de energia desta matriz.

Dentre a busca pelo uso de energias renováveis no dia a dia, a energia solar merece destaque, esta pode ser utilizada para a produção de energia elétrica ou térmica, sendo a segunda mais difundia no Brasil, através do

*Bolsista de Extensão - PROEXT - MEC

(**) Projeto desenvolvido com recursos do PROEXT 2012 - Ministério da Educação (MEC). 
uso da energia solar para o aquecimento de água para banho humano. Visto que o uso de aquecedores solares para este fim gera uma economia no consumo de energia elétrica. Sendo a classe residencial responsável por $24,8 \%$ da energia elétrica gerada no Brasil a substituição dos chuveiros por aquecedores solares levaria à uma economia considerável da energia elétrica gerada visto que o chuveiro consome de $6,2 \%$ a $8,7 \%$ do total de energia elétrica produzida no país (PROCEL, 2005).

Infelizmente, apesar de ser benéfico os sistemas de aquecedores solares (SAS) não foram difundidos no Brasil como o esperado. A resistência aos SAS está relacionada principalmente ao preço dos sistemas, visto que os sistemas convencionais possuem valores elevados devido aos materiais utilizados na sua construção.

Assim, de forma a permitir que o SAS seja uma tecnologia difundida entre toda a população, este trabalho tem como objetivo testar a eficiência energética de dois arranjos de sistemas de aquecimento solar de baixo custo, com placas planas construídas de material reciclável.

\section{EMBASMENTO TEÓRICO}

A radiação solar é a radiação originada do sol, numa temperatura de cerca de $6000 \mathrm{~K} \mathrm{e}$ em um intervalo de comprimento de onda entre $0,3 \mu \mathrm{m}$ a $3,0 \mu \mathrm{m}$, com o pico de emissão ocorrendo em aproximadamente $0,50 \mu \mathrm{m}$. A radiação de onda longa é aquela originária em fontes que estão em temperaturas próximas à ambiente com comprimentos de onda superiores a 3,0 $\mu \mathrm{m}$. Esta é a radiação emitida pela atmosfera e pela maioria das superfícies absorvedoras de energia existentes na Terra, um coletor solar ou o solo por exemplo. A radiação térmica é a fração intermediária do espectro, que se estende aproximadamente de 0,1 até $100 \mu m$ e que inclui uma fração da região UV e todo o espectro visível e infravermelho (IV) (SIQUEIRA, 2009).

A radiação solar global é medida em uma superfície horizontal. Mas para projeto de aquecedores necessita-se conhecer a radiação na superfície inclinada. Os Coletores solares de placas planas absorvem ambas as componentes diretas e difusas da radiação solar. Segundo Siqueira 2009, a radiação no plano inclinado de um coletor de orientação fixa pode ser calculada utilizando a radiação total na horizontal, porém para tal deve se conhecer a razão da radiação total em superfície inclinada pela radiação na superfície horizontal:

$R=\frac{I_{T}}{I}=\frac{I_{b}}{i} R_{b}+\frac{I_{d}}{i}\left(\frac{1+\cos \beta}{2}\right)+\rho\left(\frac{1-\cos \beta}{2}\right)$

Em que, $I_{T}$ é a radiação solar total horária em superfície inclinada $\left[\mathrm{kJ} / \mathrm{m}^{2}\right], I_{b}$ é a radiação direta horária $\left[\mathrm{kJ} / \mathrm{m}^{2}\right] ; \mathrm{R}_{\mathrm{b}}$ é a razão entre a radiação direta horária na superfície inclinada pela radiação direta horária no plano horizontal [adimensional], $\mathrm{r}$ é a refletividade do solo [adimensional], $(1+\cos \beta) / 2$ é o fator de forma do coletor de inclinação b com o céu e $(1-\cos \beta) / 2$ é o fator de forma do coletor.

Segundo Abogderah (1991), o coletor solar é uma forma de trocador de calor que transforma a energia solar em calor, tendo sua principal diferença em relação aos trocadores de calor convencionais que ao invés da troca de calor ocorrer entre dois fluidos com alta taxa de transferência de calor desprezando a radiação.

Os aquecedores utilizados no Brasil são basicamente compostos pela placa coletora e pelo reservatório térmico (boiler), adicionados das tubulações. Mas vêm sendo estudados os aquecedores solares de baixo custo com funcionamento por termo sifão, neste caso não existe o boiler, ou seja, um mesmo reservatório armazena a água fria e a água quente. De forma a facilitar o balanço de energia do reservatório, este será dividido em 3 regiões a de fundo, onde estará a água fria que alimentará o coletor, a de topo que receberá a água quente vinda do coletor, e uma região intermediária entre estas duas. Sendo que de acordo com Souza (2002). A placa coletora é o principal componente dos sistemas de aquecimento solar, visto que ela é responsável pela absorção e transferência da radiação solar para o fluido na forma de energia térmica.

No balanço de energia de um coletor solar plano a principal entrada de energia é a radiação solar. Ao incidir sobre a placa coletora parte desta energia será absorvida pela placa e parte será perdida por reflexão. Como este trabalho teve como objetivo determinar se as placas 
construídas de materiais recicláveis aqueceriam a água à temperatura considerada ótima para o banho, se apresentado apenas o balanço de energia para o reservatório, de forma a verificar se o uso de um mesmo reservatório para água quente e fria não prejudicaria o sistema.

A capacidade de armazenamento de energia de um tanque com uma temperatura uniforme operando sob uma diferença de temperatura finita é dado por:

$$
Q_{S}=\left(m c_{p}\right) \Delta T_{S}
$$

Em que $\mathrm{Q}_{\mathrm{s}}$ é a capacidade de calor total para um ciclo de operação na faixa de temperatura $\Delta \mathrm{T}_{\mathrm{s}}$, com $\mathrm{m}$ a massa de água da unidade $(\mathrm{kg})$.

Normalmente os reservatórios dos sistemas de aquecimento solar apresentam algum grau de estratificação, em que o topo do tanque fica mais quente que o fundo, podendo sugerir assim três seções que possam apresentar uma razoável aproximação entre o projeto conservativo (tanque com única seção) e a situação limite com alto grau de estratificação. Assim, o balanço de energia será feito para cada seção do tanque. $O$ resultado é um conjunto de três equações que podem ser resolvidas para as temperaturas das 3 seções como função do tempo. Assumindo que a massa de água que entra no reservatório vai de encontro à camada de água que apresenta uma densidade aproximadamente igual. Bem como essa quantidade de água ao entrar no tanque pode distribuir-se no caminho pelas outras seções do tanque.

Para as três seções do tanque dividido em camadas de mesma altura, com uma temperatura uniforme em cada uma delas, como apresentado na Figura 1, o fluxo de água para o coletor sempre sai do fundo, seção 3 com temperatura $T_{3}$, e o fluxo para o consumo sempre sai do topo, seção 1 com temperatura $T_{1}$. O fluxo que sai do coletor, à temperatura $T_{s}$, retornará para a seção que está mais próxima da temperatura de saída do coletor.

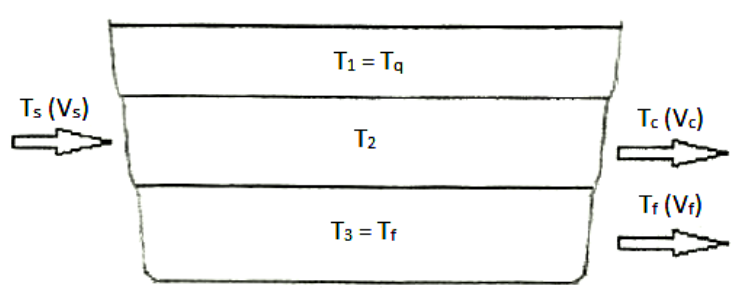

\section{Figura 1 - Desenho esquemático de reservatório}

Considerando que a perda de calor é distribuída igualmente entre as camadas do reservatório, estas podem ser calculadas pelo coeficiente global de perdas de calor:

$U_{r}=\frac{Q_{\text {perdido }}}{A_{r}\left(T_{r m}-T_{a}\right)}$

Sendo, $A_{r}=2 A_{t}+A_{L}=2 \pi r(h+r)$

em que $r$ é o raio do cilindro e $h$ sua altura; $T_{r m}$ é a temperatura media do reservatório (calculada por média aritmética), $T_{a}$ é a temperatura ambiente e $Q_{\text {perdido }}$ é o calor total perdido devido à transferência de calor para o meio ambiente através do topo e da lateral do reservatório.

A mistura do volume de água quente $\left(V_{q}\right)$ à temperatura $T_{1}$ com o volume de água fria $\left(V_{f}\right)$ à temperatura $T_{f}$, determina o volume de água para consumo $\left(V_{c}\right)$ em cada hora a uma temperatura de consumo $T_{q}$ préestabelecida. Portanto é conhecido $T_{f}$ e $T_{1}$ $\left(T_{1}=T_{q}\right)$ a serem misturadas para se obter $T_{c}$.

Ao relacionar os volumes considerados em cada seção com as temperaturas correspondentes chega-se a seguinte igualdade:

$$
T_{c} V_{c}=T_{f} V_{f}+T_{q} V_{q}
$$

Como:

$$
V_{c}=V_{f}+V_{q}
$$

Isolando $\mathrm{V}_{\mathrm{f}}$ na Equação 6 e substituindo na Equação 5, obtemos:

$$
V_{q}=\frac{V_{c}\left(T_{e}-T_{f}\right)}{T_{q}-T_{f}}
$$


A temperatura no reservatório é determinada pela troca de calor entre as três seções. Na seção 1 ouve perda de calor para a seção 2. A equação que relaciona essa perda de calor $\left(\mathrm{Q}_{1-2}\right)$ é dada por:

$$
Q_{1-2}=V_{q} C_{p}\left(T_{2}-T_{1}\right)
$$

O calor útil $\left(\mathrm{Q}_{\mathrm{u}}\right)$ agregado a água que sai do reservatório $\left(\mathrm{T}_{3}=\mathrm{T}_{\mathrm{f}}\right)$ é obtido pela variação da temperatura vinda do coletor e vazão mássica de saída (considerando constante em uma hora), demonstrado abaixo:

$$
Q_{u}=V_{s} C_{p}\left(T_{f}-T_{\theta}\right)
$$

Considerando que a massa de água que sai do coletor entra na camada intermediária do reservatório, que por sua vez está a uma temperatura maior em relação a $T_{2}$, tenderá a se deslocar para a superfície, já que há diferença de densidade. Assim a quantidade de calor agregado à água superficial a cada hora é: $\mathrm{V}_{\mathrm{s}}\left(\mathrm{T}_{\mathrm{s}}-\mathrm{T}_{1}\right)$.

Abaixo segue as equações que relacionam o balanço energético de cada camada. Em que as duas primeiras parcelas da fração são relacionadas a perda de calor e a terceira ao ganho de energia.

Camada 1:

$$
\begin{aligned}
& T_{1}^{+} \\
& =T_{1} \frac{V_{q} C_{p}\left(T_{2}-T_{1}\right)-\frac{Q_{P e r d i d o}}{3}+V_{s} C_{p}\left(T_{s}-T_{e)}\right.}{m C_{p}}
\end{aligned}
$$

Camada 2:

$$
\begin{aligned}
& T_{2}^{+} \\
& =T_{2} \frac{V_{q} C_{p}\left(T_{3}-T_{2}\right)-\frac{Q_{P_{\text {erdido }}}}{3}+V_{s} C_{p}\left(T_{1}-T_{2)}\right.}{m C_{p}}
\end{aligned}
$$

Camada 3:

$$
\begin{aligned}
& T_{3}^{+} \\
& =T_{3} \frac{V_{q} C_{p}\left(T_{f}-T_{3}\right)-\frac{Q_{\text {Perdido }}}{3}+V_{s} C_{p}\left(T_{2}-T_{3}\right)}{m C_{p}}
\end{aligned}
$$

\section{METODOLOGIA}

\section{Dimensionamento}

Para que o aquecedor seja eficiente é necessário ter uma garrafa PET cristal de 2 litros para cada litro de água do reservatório (Alano, 2004).

Para a construção das placas coletoras foi utilizado canos de PVC de $20 \mathrm{~mm}$ de diâmetro, conectadas por " $\mathrm{T}$ " para atingir o formato apresentado na Figura 2. Os canos foram pintados de preto fosco, e então envolvidos com garrafa PET de forma a propiciar o "efeito estufa" no cano, dentro desta garrafa foi adicionada uma embalagem cartonada com o alumínio perpendicular a incidência do sol, de forma a refletir a luz para os canos que pintados de preto absorveriam esta luz.

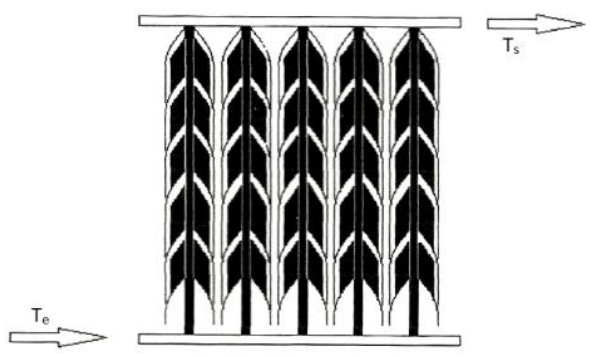

Figura 2 - Desenho esquemático da placa coletora

A caixa d'água teve que ser adaptada para facilitar o termo sifão (Figura 3). Esta adaptação consistiu na instalação da flange de $3 / 4$, na parte superior ( $80 \%$ da altura), para abastecimento de água, dois na parte intermediária, um de frente para o outro $(60 \%$ da altura), para consumo e para entrada de água quente, proveniente do painel aquecedor e o quarto na parte inferior (10\% da altura), para a saída de água fria para o painel. Também foi conectada uma boia juntamente com uma mangueira e um redutor de turbulência, para forçar que a água fria fosse direto para o fundo do reservatório e não houvesse mistura da água.

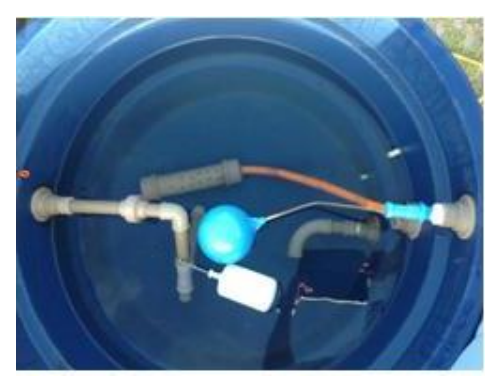

Figura 3 - Interior do reservatório. 
Paine de placas planas com conexões do tipo paralela: Para este painel, foram cortadas 20 varas de cano de $108 \mathrm{~cm}$ e 42 pedaços de cano de $8 \mathrm{~cm}$ de comprimento. Fixou-se com cola de PVC as varas nas conexões do tipo "T" juntamente com 21 pedaços de $8 \mathrm{~cm}$, chegando à estrutura da Figura 2. Após a introdução das garrafas e caixas catonadas, os conectores "T" da parte inferior, foram conectados, porém não colados para futuras manutenções.

Painel de placas planas com conexões do tipo serpentina: Este painel se diferencia do outro apenas na quantidade de varas de cano e no tipo de conexão. Para os canos de PVC, foram cortados 19 varas e 20 pedaços de cano de $8 \mathrm{~cm}$ de comprimento. Fixou-se com cola de PVC as varas nas conexões do tipo cotovelo de $20 \mathrm{~mm}$ juntamente com os pedaços de $8 \mathrm{~cm}$, de forma que a água no interior do tubo passasse por todas as varas do sistema.

\section{RESULTADOS E DISCUSSÕES}

Com o protótipo pronto e posto em operação nos dias ensolarados, foram coletados os valores de temperatura da água com o intervalo de tempo de 20 minutos, durante o período de $8 \mathrm{~h}$ às $16 \mathrm{~h} 40 \mathrm{~min}$.

O painel com conexões do tipo paralelas apresentou uma crescente temperatura no reservatório em conjunto com o aumento da temperatura ambiente, atingindo uma temperatura máxima de $42^{\circ} \mathrm{C}$ as $15 \mathrm{hrs}$ como mostra a Figura 4.

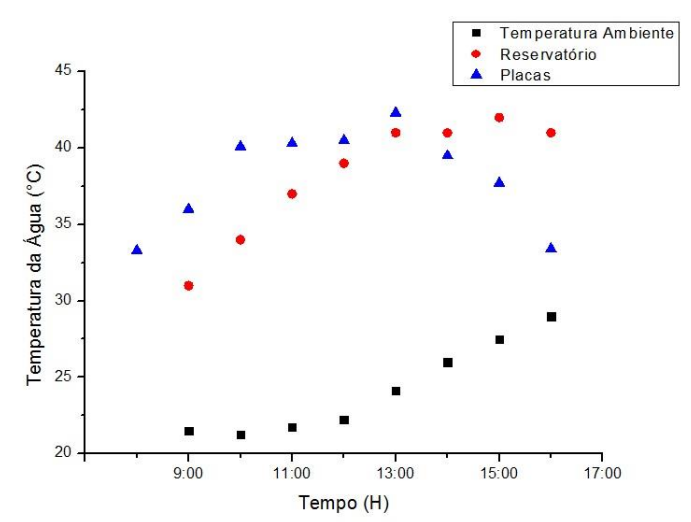

\section{Figura 4 - Perfil de temperatura para o painel com conexões do tipo paralela}

Pode ser observado também que após atingir a temperatura máxima mesmo com o aumento da temperatura ambiente a temperatura das placas caiu consideravelmente, este fenômeno está atribuído a mudança da posição do sol, visto que no inicio das medições a posição do sol favorecia a incidência dos raios solares na placa, as velocidades do vento no período da tarde também foram superiores às da manha e inicio da tarde. Porém pode se observar que mesmo com o decaimento da temperatura das placas a temperatura do reservatório foi mantida próxima aos $40^{\circ} \mathrm{C}$, temperatura esta considera ideal para o banho humano.

A curva do gráfico que representa o painel possui oscilações mais acentuadas em relação a curva do reservatório, isso ocorreu devido as placas serem mais sensíveis as interferências do clima, como diminuição da incidência solar, presença de nuvens e a ocorrência de ventos mais intensos, e o mesmo não aconteceu com o reservatório.

O perfil de temperatura do painel com conexões do tipo serpentina pode ser visto na Figura 5.

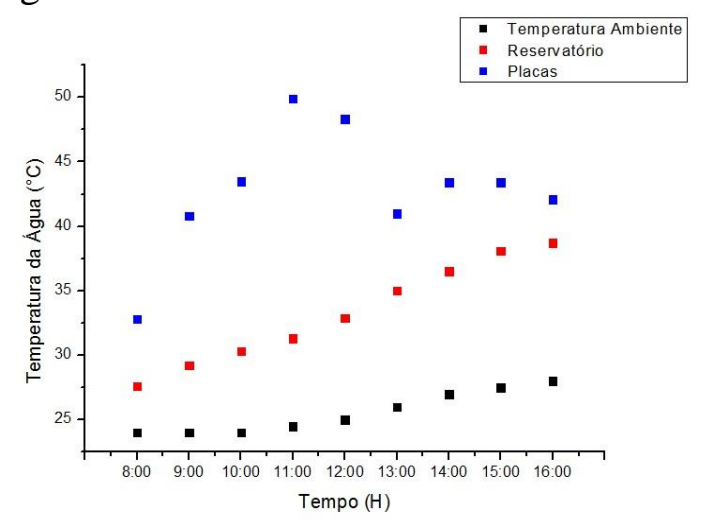

Figura 5 - Perfil de temperatura para o painel com conexões do tipo serpentina.

A Figura 5 mostra que a curva que representa a variação de temperatura no painel possui um abrupto decaimento no período de $11 \mathrm{~h}$ e $13 \mathrm{~h}$. Isso ocorreu devido à inexistência do fluxo de água entre o reservatório e o painel neste período de tempo, levando a problemas de amolecimento do cano de PVC e, posteriormente, rachadura do mesmo. Isto também ocorreu durante outros dias de coleta de dados, tornando esta técnica menos viável para residências.

A curva de temperatura ambiente apresenta um crescimento que é acompanhado pela curva de temperatura do reservatório, atingindo um máximo de $38,7^{\circ} \mathrm{C}$ às $16 \mathrm{~h}$ no reservatório. Isso ocorreu devido ao fato de o 
fluxo de água já estar normalizado e a ainda existir radiação incidente significativa. Esta temperatura está um pouco abaixo da temperatura ideal, mas pode ser considerada uma boa temperatura para o banho humano.

A título de comparação, podemos observar, na figura 8 , que a temperatura nos dois reservatórios tem comportamento semelhante, alcançando temperaturas próximas e que satisfazem a temperatura proposta de $40^{\circ} \mathrm{C}$, se sobressaindo por alguns graus, o painel com conexões do tipo paralelo, que possui uma maior capacidade de aquecer a água.

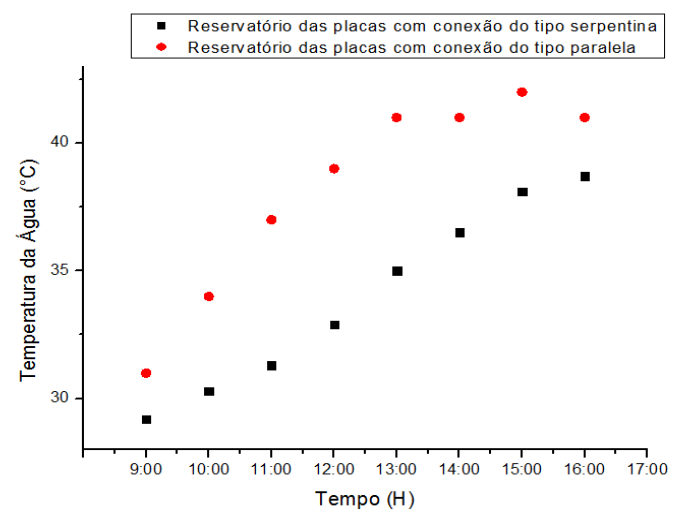

Figura 8 - Curva dos reservatórios dos dois painéis.

Usando as equações 4 e 3, citadas no equacionamento deste estudo, para encontrar o coeficiente global de perda de calor (Ur) e o calor perdido $\left(\mathrm{Q}_{\text {perdido}}\right)$, respectivamente, para o reservatório no pico de temperatura do painel com conexões do tipo paralela, pois o mesmo apresentou melhor temperatura para o banho humano.

Considerando $r=1,47 \mathrm{~m}$ encontramos os valores para os coeficientes globais de perda de calor igual a 3,62 e 3,64 e de perda de calor igual a 42,04 e 84 para os sistemas em serpentina e em paralelo respectivamente.

De acordo com os dados apresentados anteriormente, podemos observar que a perda de calor é diretamente proporcional à diferença entre a temperatura média da caixa d'água e a temperatura ambiente. Com isso houve uma maior perda de calor no reservatório do painel que possui ligação em paralela devido a maior diferença entre as temperaturas.

\section{CONCLUSÃO}

Com todos os testes realizados e os dados analisados, podemos concluir que o painel de placas planas com conexões do tipo paralelo alcançou temperaturas próximas a da ideal para o banho humano, sendo necessário haver uma mistura de água para não haver problemas na pele, além de não terem sido encontrados problemas significativos com amolecimento de canos e interrupções de fluxo.

O painel de placas planas com conexões do tipo serpentina é um painel que atingiu boas temperaturas, porém houve problemas relacionados a interrupção de fluxo de água que levaram a problemas de amolecimento de cano e rupturas nos mesmo.

Portanto, o painel de placas planas com ligações em paralelo é mais vantajoso visto que o mesmo não necessita de cuidados contínuos com as placas e atingiu temperaturas muitas próximas da idealidade requerida.

\section{REFERÊNCIAS}

ALANO, J. A. (2004), Manual sobre a construção e instalação do aquecedor solar com descartáveis. Tubarão, Santa Catarina, Brasil.

BUDIN, S. M. (2009), A matriz energética brasileira, mitos e realidade. Publicado por HC, Brasil.

CABIROL, T. (1980), O aquecedor solar de água. Lisboa: Edições Cetop.

GOLDEMBERG, J.; LUCON, O. (2007), Energias renováveis: um futuro sustentável. Publicado na revista USP, $\mathrm{n}^{\circ}$ 72, São Paulo, Brasil.

SPRENGER, R. L. (2007), Aplicação do sistema fechado no aquecedor solar de água de baixo custo para reservatórios residenciais isolados termicamente: concepção e comissionamento de um sistema-piloto de testes. Curitiba, Brasil.

Site: www.sempresustentavel.com.br - site visitado em 16/09/2013 as 13:15.

\section{AGRADECIMENTOS}

Agradecemos a Pró-Reitoria de Extensão (ProEx) pelo financiamento das bolsas e dos materiais utilizados. 